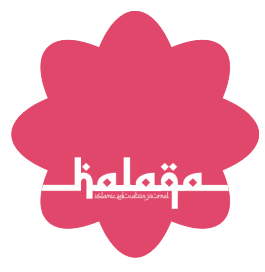

OPEN ACCESS ISSN 2503-5045 (online) ISSN 1412-9302 (print)

Edited by: Eni Fariyatul Fahyuni

Reviewed by: Khozin ${ }^{*}$ Correspondence: Wasehudin Wasehudin mesiono@uinsu.ac.id

Received: 5 Oktober 2020 Accepted: 12 Oktober 2020 Published: 25 Oktober 2020

Citation:

Wasehudin W (2020) Pancasila as The Code of Conduct Paradigm (Comparative Study of National Education And Islamic Studies). HALAQA. 4:2.

doi: 10.21070/halaqa.v4i2.983

\section{Pancasila as The Code of Conduct Paradigm (Comparative Study of National Education And Islamic Studies)}

\section{Pancasila sebagai Paradigma Kode Etik (Studi Banding Pendidikan Nasional Dan Kajian Islam)}

\author{
Wasehudin Wasehudin* \\ The State Islamic University Sultan Maulana Hasanuddin Banten, Indonesia
}

The undermined to Pancasila, as the final basic and the only Indonesia five fillars, always comes on behalf of a certain religious. This legitimates a certain purpose of those who are neither responsible or unappreciated to the independency of Republic of Indonesia lays form Sabang to Marouke. Pancasila as this national basis of Indonesia owns two dimensions; firstly, pancasila must develop mission and values of Godness as it is derived from first pillar. Secondly, Pancasila has its human dimension or human touch at which this dimension derived from second until fifth pillar, at which the national characters runs on and create justice and prosperious of the nation. These constitute the highest value of Pancasila in creating Indoensia human resource. It is the same as how Islamic education values at which 'akhlak', good characters (In English) as the basic pillar of Nabi Muhammad SAW as the God messenger that create the justice and social values. It is clear that Pancasila as code of conduct for both national education and Islamic education. Both drive through the same vision and mission to which as believed human being to God and those who have good characters as the main purposes of the both.

Keywords: Pancasila, Code Of Conduct, And Islamic Education

Rongrongan terhadap Pancasila sebagai satu-satunya Dasar bagi bangsa Indonesia yang bersifat final seringkali mengatasnamakan agama tertentu sebagai jargon untuk melegitimasi kepentingan sepihak terutama bagi mereka yang tidak bertanggung jawab dan menghargai perjuangan para pendiri bangsa Republik Indonesia tercinta dari Sabang hingga Meraoke. Pancasila sebagai Dasar Negara bagi Bangsa Indonesia memliki dimensi ganda, dimana dimensi pertama, Pancasila harus mengembangkan misi serta nilai-nilai ke-Tuhanan sebagaimana yang tertera pada sila pertama; kedua, berdimensi kemanusian, dimana pada dimensi ini mulai dari Sila kedua hingga kelima, penanaman nilai-nilai karakter bangsa hingga terciptanya keadilan dan kemakmuran di negeri ini merupakan amanat serta nilai luhur dari Pancasila itu sendiri dalam membentuk Sumber Daya Manusia (SDM) Indonesia seutuhnya. Begitu juga dengan tujuan pendidikan 
islam dimana akhlak sebagai pilar utamanya ke-Nabian Muhammad SAW dapat membuahkan keadilan maupun kesolehan sosial, disitulah terlihat dengan jelas dan gambelang bahwasannya Pancasila sebagai Code of Conduct baik bagi pendidikan nasional maupun pendidikan Islam karena keduanya bermuara pada satu visi dan misi dimana manusia yang beriman dan bertaqwa kepada Tuhan Yang Maha Esa serta berakhlak mulia menjadikan tujuan utama dari keduanya.

Kata Kunci: Pancasila, Code of Conduct, Pendidikan Islam 


\section{PENDAHULUAN}

Menteri Pendidikan Nasional di era tahun 2009, Bambang Sudibyo menyatakan bahwasannya pendidikan merupakan media yang sangat ampuh bagi sebuah negara untuk mengejar ketertinggalannya baik dalam bidang sains, teknologi hingga keterpurukan ekonomi sekalipun, sehingganya komitmen seperti ini ia seriusi dengan berbagai bentuk kebijakan dalam bentuk program yang senantiasa diarahkan untuk mencapai satu tujuan meningkatnya sumber daya manusia yang berperadaban. Salah satu bentuk keseriusan dari seorang menteri dalam memajukan dunia pendidikan ia tetap berkomitmen untuk mengadakan perubahan serta melaksanakan dari berbagai Undang-undang seperti halnya Undang-undang Sistem Pendidikan Nasional (SISDIKNAS) Nomor 20 Tahun 2003, Undang-undang Nomor 14 Tahun 2005 tentang guru dan dosen hingga Undang-undang Nomor 9 Tahun 2009 tentang Badan Hukum Pendidikan yang mempunyai komitmen banhwasannya anggaran pendidikan baik dari APBN maupun APBD tidak kurang dai 20\% dalam pengalokasiannya.[Sambutan Kata Pengantar pada karya Moh Ali, Pendidikan untuk Pembangunan Nasional Menuju Bangsa Indonesia yang Mandiri dan Berdaya Saing Ting]

Pasca Reformasi Tahun 1998 diharapkan dapat membawa perubahan serta dapat menghantarkan bangsa Indonesia pada gerbang peradaban yang berkemajuan (civil society) yang penuh dengan keadilan dan kemakmuran. Untuk mewujudkan semua itu tentunya tidak bisa dilepaskan dari tujuan pendidikan nasional itu sendiri. Salah satu visi pembangunan nasional bangsa Indonesia tahun 2005-2025 sebagaimana yang tertuang dalam Undang-Undang Nomor 17 Tahun 2007 adalah mewujudkan masyarakat Indonesia yang berakhlak mulia, bermoral, beretika, berbudaya, dan beradab yang berlandaskan pada falsafah Pancasila sebagai Dasar Negara kesatuan Republik Indonesia. Begitu pula dengan arah pendidikan yang dikembangkan bagi bangsa Indonesia, khususnya dalam dunia pendidikan Islam hendaknya mengacu pada bangunan tatanan yang sejalan dengan nilai-nilai Pancasila yang secara sah menjadi dasar negara kesatuan Republik Indonesia. Dengan demikian kelembagaan pendiidkan Islam seperti halnya madrasah dan pondok pesantren menjadikan Pancasila sebagai civic education yang mengarah pada model pembangunan demokrasi yang berkeadaban sebagaimana yang telah diamanatkan dalam penjelasan atas Undang-undang Sistem Pendidikan Nasional (SISDIKNAS) Nomor 20 Tahun 2003: "Pendidikan nasional berfungsi mengembangkan kemampuan dan membentuk watak serta peradaban bangsa yang bermartabat dalam rangka mencerdaskan kehidupan bangsa, bertujuan untuk berkembangnya potensi peserta didik agar menjadi manusia yang beriman dan bertaqwa kepada Tuhan Yang Maha Esa, berakhlak mulia, sehat, berilmu, cakap, kreatif, mandiri, dan menjadi warga negara yang demokratis serta bertanggung jawab"

Ironisnya pasca reformasi gaung Pancasila seakan telah meredup berbeda di era ORDE Baru dimana penataran P4 pola pendukung serratus jam menjadi prasyarat bagi mahasiswa baru, begitu juga seseorang belum dikatakan Pancasilais jika seseorang belum mengikuti penataran P4 Ibrahim (2010) . Kesaktian Pancasila seolah-olah telah meluntur seiring berjalannya era reformasi; ia tidak lebih hanya sekedar bacaan mingguan dan tahunan; dihari-hari dimana apel para siswa setiap hari senin dilaksanakan, juga dibulan Juni sebagai bulan kesaktian Pancasila itu sendiri. Popularitas Pancasila telah mengalami kemerosotan atau setidaknya meminjam istilah Mahfud MD bahwasannya gema Pancasila sudah sangat mengendur di era reformasi ini. MD (2011)

Pancasila sebagai dasar negara bagi bangsa Indonesia bertujuan untuk mewujudkan rasa keadilan dan kesejahteraan bagi rakyatnya dari Sabang hingga Meroeke dengan tetap menjunjung tinggi nilai-nilai Ke-Tuhanan Yang Maha Esa serta kemanusiaan yang adil dan beradab bagi seluruh rakyat Indonesia. Terwujudnya kesejahteraan dan keadilan bagi seluruh bangsa Indonesia manakala Pancasila dijadikan sebagai cita-cita hukum (rechtsidee) tertinggi bagi bangsanya. Ibrahim (2010)

\section{METODE}

Penelitian ini merupakan penelitian dengan menggunakan metode studi kepustakaan atau literatur review. Literatur review adalah ikhtisar komprehensif tentang penelitian yang sudah dilakukan mengenai topik yang spesifik untuk menunjukkan kepada pembaca apa yang sudah diketahui tentang topik tersebut dan apa yang belum diketahui, untuk mencari rasional dari penelitian yang sudah dilakukan atau untuk ide penelitian selanjutnya Denney and Tewksbury (????) . Studi literatur didapat dari berbagai sumber baik jurnal, buku, dokumentasi, internet dan pustaka. Jenis penulisan yang digunakan adalah studi literatur review yang berfokus pada hasil penulisan yang berkaitan dengan topik atau variabel penulisan. Penulis melakukan studi literatur ini setelah menentukan topik penulisan dan ditetapkannya rumusan masalah, sebelum terjun ke lapangan untuk mengumpulkan data yang diperlukan.

\section{PEMBAHASAN}

\section{Peran Strategis Pancasila}

Maraknya "madhab hoaxisme"dikalangan pengguna medsos (mulai dari pelajar hingga masyarakat biasa) akhir-akhir ini merupakan suatu bukti kegagalan dari pola, model maupun corak pendidikan yang selama ini diterapkan di negara ini, dimana pola yang dibangun oleh para penentu kebijakan maupun pelaku pendidikan (guru) sebelumnya lebih menitikberatkan pada aspek pengetahuan (cognitive domain) sementara pembentukan kepribadian yang sejalan dengan nilai-nilai Pancasila terlupakan atau dalam istilah agama penanaman nilai-nilai akhlak yang bermuara pada aspek keihsanan malah terabaikan. Pola bangunan maupun corak pendidikan nasional 
di negeri ini lebih mengejar kuantitas masyarakat melek sekolah seperti halnya kebijakan pemberantasan buta huruf hingga bertitel sarjana maupun corak pendidikan yang tertumpu pada pola maupun model pembelajaran (style) guru dalam menyampaikan pembelajaran di kelasnya, begitu juga dengan persoalan nasib guru yang kurang sejahtera hingga harus diperjuangkan sampai disetarakan dengan negara-negara maju seperti Singapura, Jepang dan Korea, melainkan bagaimana lembaga pendidikan baik sekolah, madrasah maupun pondok pesantren lebih diberi makna sebagai agen penyemaian moralitas maupun akhlak anak bangsa yang mampu melihat serta mamahami peristiwa hari ini baik yang sedang terjadi maupun yang akan terjadi dengan menjadikan sejarah sebagai tolak ukur dalam meretas masyarakat yang berkemajuan pada masa yang akan datang.

Ada dua alasan mendasar mengapa Pancasila harus dijadikan sebagai Dasar bagi bangsa Indonesia: Pertama, Pancasila mempunyai flatform yang ideal bagi kehidupan bangsa yang majemuk bangsa yang didalamnya terdiri dari suku, rasa, bahasa, bahkan agama yang berbeda dan kemajemukan tersebut hanya bisa diikat dengan Pancasila; dan kedua, Pancasila sebagai sebuah Dasar bagi bangsa Indonesia sudah termuat dalam Pembukaan Undang-undang Dasar 1945 yang di dalamnya ada kemerdekaan bagi bangsa Indonesia. Antara Pancasila dan Undang-undang Dasar 1945 adalah satu kesatuan yang tidak dapat dipisahkan dalam arti jika Pancasila dirubah, maka Undang-undang Dasar 1945 juga harus dirubah dan jika Undang-undang Dasar 1945 dirubah maka kemerdekaan yang pernah dinyatakan dalam pembukaan Undang-undang Dasar 1945 tersebut dianggap menjadi tidak ada lagi atau Indonesia menjadi bubar. Dengan demikian Pancasila selain sebagai Dasar Negara juga sebagai alat pemersatu yang mampu mengikat serta memposisikan dirinya sebagai tempat kembali jika bangsa ini terancam perpecahan. [Sambutan Kata Pengantar pada karya Moh Ali, Pendidikan untuk Pembangunan Nasional Menuju Bangsa Indonesia yang Mandiri dan Berdaya Saing Ting]

Pancasila sebagai sebuah dasar negara tidaklah cukup hanya sebatas pengakuan semata akan tetapi terimplementasi nilai-nilai Pancasila dalam kehidupan nyata merupakan asas hakiki yang harus dipegang teguh oleh setiap bangsa Indonesia. Oleh karenanya proses rekonseptualisasi Pancasila sebagai dasar negara merupakan tugas bersama dari Sabang hingga Maroeke. Pendidikan islam sebagai sebuah institusi mempunyai tanggung jawab serta andil yang sangat besar agar perilaku bangsa ini tidak lagi bertentangan dengan nilai-nilai luhur yang terkandung di dalam Pancasila itu sendiri. Hal ini didasarkan bukan hanya pada fungsi dan peran pendidikan keagamaan secara an sich dalam upaya mempersiapkan peserta didik menjadi anggota masyarakat yang dapat memahami serta mengamalkan nilai-nilai ajaran agama melainkan juga pemahaman keagamaan yang tidak disalahartikan sebagimana yang dilakukan oleh sebagian kecil dari kalangan ekstrimis, dimana pemahaman keagamaan secara parsial yang kemudian dijadikan dasar untuk menjustufikasi kebenaran sepi- hak. Oleh karenanya kelembagaan pendidikan islam dalam menanamkan nilai-nilai Pancasila sebagai Dasar Negara bagi bangsa Indonesia harus menjadi pilar utama serta bagian dari pendidikan islam itu sendiri.

Disisi lain Pancasila hendaknya dijadikan sebagai paradigma pembangunan politik dimana bangsa Indonesia selaku warga negara harus menempati posisi sebagai pelaku politik bukan objek politik. Dengan demikian pembangunan politik akan berimbas pada tatanan meningkatnya harkat maupun martabat manusia sebagai warga bangsa, oleh karenanya perwujudan manusia menjadi subjek akan menempatan kekuasaan tertinggi kepada rakyat karena inti dari struktur yang dibangun dalam pola kepemimpinan hendaknya bermula dan bermuara dari rakyat, oleh rakyat dan untuk rakyat. MD (2011)

Meminjam istilah yang dipaparkan oleh Azyumardi Azra kendatipun Rejuvenasi Pancasila bukan sesuatu hal yang mudah untuk dilaksanakan namun kita harus tetap optimis menjadikan Pancasila sebagai common flatform bagi ideologi bangsa Indonesia yang akan membawa bangsa ini pada tataran yang paling feasible baik bagi kehidupan bangsa hari ini maupun pada kehidupan yang akan datang. Oleh karenanya tugas dan tanggung jawab pemerintah dalam bidang pendidikan hendaknya menjadi sekala prioritas; pendidikan bukan sekedar mengajarkan ilmu pengetahuan (transfer of knowledge) semata akan tetapi penanaman nilai-nilai karakter, budi pekerti maupun akhlaul karimah hendaknya menjadi garda terdepan dalam rangka menggapai keadilan social bagi seluruh rakyat Indonesia. Islam (2011)

\section{Pancasila sebagai Paradigma Code of Conduct}

Dalam ketetapan MPRS Nomor IV/MPR/1973 Bab II Ayat 3 dinyatakan bahwasannya tujuan utama pendidikan bagi bangsa Indonesia adalah menyiapkan manusia yang berjiwa Pancasila sebagaimana yang diamanatkan dalam Undangundang dasar Negara Republik Indonesia Tahun 1945. Dengan demikian tujuan maupun cita-cita Negara Kesatuan Republik Indonesia adalah membentuk masyarat Indonesia yang adil dan makmur berdasarkan Pancasila. Tujuan tersebut secara definitif tertuang dalam pembukaan Undang-undang Dasar 1945 alinea keempat yang mencakup:

- Melindungi segenap bangsa dan seluruh tumpah darah Indonesia;

- Memajukan kesejahteraan umum;

- Mencerdaskan kehidupan bangsa; dan

- Ikut melaksanakan ketertiban dunia, berdasarkan kemerdekaan, perdamaian abadi, dan keadilan sosial.

Paradigma secara bahasa berarti model, teori ilmu pengetahuan atau kerangka berfikir. Pendidikan (2007) Dari sinilah kemudian para ahli mengembangkan definisi dari paradigma menjadi acuan, tolak ukur, pijakan, parameter, arah maupun 
tujuan dari sebuah tindakan. PENDIS (2011) Paradigma juga bisa diartikan sebagai cara pandang dari seorang ilmuan yang menitikberatkan pada satu titik pokok persoalan yang harus dicarikan jawabannya. Raho (2007) Sedangkan yang dimaksud dengan Code of Conduct ( $\mathrm{CoC})$ merupakan sebuah "kumpulan asas, prinsip, nilai, dan standar etis (value statement) yang berhubungan dengan akhlak dan moralitas pemangku kepentingan. Asas dan prinsip ini dirumuskan sedemikian rupa sehingga memadadi untuk dipakai sebagai pedoman atau patokan untuk bertindak". Wenehen (2012) Dengan demikian prinsip pengembangan prilaku seseorang harus berdasarkan pada integritas moral yang dilandaskan pada nilai-nilai kejujuran, tanggung jawab, berkeadilan yang saling menguntungkan. Gagasan maupun pola bangunan dari Code of Conduct (CoC) bukan hanya didasarkan pada norma agama semata, melainkan juga adat istiadat yang dianutnya dan ini berlaku untuk semua warga sekolah inklud di dalamnya orang tua (wali murid) dan masyarakat.

Indonesia sebagai negara yang majemuk Pancasila sebagai falsafah bangsa maupun sebagai Code of Conduct merupakan satu-satunya dasar yang dianggap bisa mewadahi semua pihak dan sudah menjadi consensus bagi para founding fathers dimana Pancasila diharapkan dapat menjadi lem perekat bagi semua suku bangsa, adat-istiadat, Bahasa maupun agama. Citacita luhur para pendiri bangsa (founding fathers) sejak negeri ini merdeka hingga sekarang implementasi nilai-nilai Pancasila dalam berbangsa dan bernegara sering ali mendapatkan hambatan terlepas dari kepentingan politik salah satu golongan maupun kepentingan lainnya yang mencoba mencederai Pancasila dalam bentuk manipulasi demi satu kekuasaan dengan mengesamping nilai-nilai luhur dari Pancasila itu sendiri. Widowati (2019)

\section{Tujuam Pendidikan Nasional dan Pendidikan Islam dalam Sebuah Perjumpaan}

Perdebatan antara kaum nasionalis dengan religious bukan berakhir pada masa kemerdekaan ketika mereka merumuskan Pancasila sebagai dasar Negara Kesatuan Republik Indonesia, namun perhelatan tersebut masih tetap ada hingga hari ini. Untuk merumuskan satu tujuan pendidikan nasional sebagai mana tertera dalam Undang-undang SISDIKNAS Nomor 20 Tahun 2003 bukan sesuatu yang mudah melainkan melalui perdebatan yang panjang yang dilakukan oleh para wakil rakyat baik yang mewakili kaum nasionalis maupun religious, mereka punya kepentiangan yang berbeda dan Undang-undang lah yang akan menjadi barometer hitamputihnya wajah pendidikan bangsa Indonesia pada masa mendatang. Fuad and Jurnalica (2012) Begitu juga dengan terbentuknya manusia yang beriman dan bertaqwa kepada Tuhan Yang Maha Esa bukanlah suatu hal yang bersifat serta merta melainkan melalui proses pendidikan baik dalam pendidikan rumah tangga (keluarga), masyarakat maupun pendidikan melalui institusi sekolah/madrasah

Konsep pendidikan islam, banyak ragam di antara para ahli pendidikan islam dalam mendefinisikan apa itu pendidikan islam? Tanpa bermaksud masuk lebih dalam pada penggunaan istlah yang dianggap tepat maupun sesuai dengan konsep islam bagi makna pendidikan sebagaimana yang digagas oleh Syed Moh Naquib Al-Attas dalam mengistilah kata Arab yang dianggap tepat dan sesuaikan dengan makna yang terkandung didalamnya seperti halnya tarbiyah, ta'lim dan ta'dib. al Attas (1980) Namun dalam hal ini lebih menitik beratkan pada inti maupun fungsi serta peran pendidikan islam itu sendiri dalam membangun wacana kemanusiaan. Azyumardi Azra dengan mengutip pendapat Yusuf Al-Qardhawi bahwasannya yang dimaksud dengan pendidikan islam adalah "pendidikan manusia seutuhnya, akal dan hatinya, rohani dan jasmaninya, akhlak dan keterampilannya. Karena itu pendidikan islam menyiapkan manusia untuk hidup baik dalam keadaan damai maupun perang, dan menyiapkan untuk menghadapi masyarakat dengan segala kebaikan dan kejahatannya, manis dan pahitnya". Azra (2012)

Pendidikan agama yang selama ini diajarakan lebih menekankan pada aspek hafalan kaidah-kaidah keagamaan pada akhirnya kurang memiliki relevansi dalam mewujudkan perubahan sosial menuju manusia susila sebagaimana yang dicita-citakan. Dengan demikian pola perombakan dalam mengajarkan pendidikan agama islam merupakan suatu hal yang tidak lagi bisa ditawar-tawar lagi dimana materi kePAI-an harus memiliki nilai-nilai maupun sepirit kebangsaan yang kelak dapat melahirkan sifat toleran, pluralis, humanis hingga egalitarian. Disinilah wajah pendidikan islam yang sesungguhnya. Mảrifah (1996) Fenomena kegagalan yang selama ini terjadi terutama dari kalangan yang beraliran keras maupun aliran kiri (teroris maupun ekstrimis) sering disebabkan oleh penafsiran yang sengaja dibenturkan antara nilainilai luhur Pancasila dengan Al-Qurán dan Al-Hadits sebagai dasar maupun sumber dari ajaran islam itu sendiri padahal nilai-nilai luhur dari Pancasila maupun Al-Qurán dan AlHadits mempunyai semangat yang sama, yaitu membangun serta menjunjung tinggi nilai-nilai kemanusiaan yang berkeadilan dan berkeadaban.

Sejak kelahirannya; Islam telah memproklamirkan sebagai agama rahmatan li al-álamien dimana islam dengan sendirinya akan senantiasa menebarkan kesolehan sosial bagi tatanan kehidupan kemanusiaan dijagad raya ini. Dalam UUD 1945, Pasal 29 Ayat 1 dikatakan bahwasannya Negara Republik Indonesia berdasarkan kepada Ke Tuhanan Yang Maha Esa dan dalam keyakinan umat islam ke Tuhanan Yang Maha Esa tidak lain adalah makna Tauhid itu sendiri, oleh karenanya pendalaman akan pemaknaan dari seumber sebagaimana yang tertera dalam UUD 1945 tersebut merupakan bagian dari proses pengembangan manusia Indonesia dengan ciri utamanya beriman serta bertaqwa kepada Tuhan Yang Maha Esa. Oleh karenanya dalam tataran paradigma pendidikan islam pengembangan sifat Rahman dan Rahim antara Tauhid Uluhiyah yang berdimensi vertikal (rahimiyah) dan horizontal (rohmaniyah) 
hendaknya dijadikan sebagai bangunan paradigma yang dapat mempengaruhi perilaku kehidupan sehari-hari baik santun terhadap sesame maupun santun terhadap ciptaan-Nya (alam semesta). Bagi Dawam Rahardjo bahwasannya tujuan pendidikan Islam adalah memburu keridhoan Allah SWT, oleh karenanya bagi para pemuda harus senantiasa dibekali nilainilai ketauhidan sebagai penguatan idiologi ketauhidan yang merupakan pilar dari pendidikan Islam itu sendiri. Rahardjo (2007) Menurut Faisal Ismail setidaknya ada enam prinsip yang dapat membedakan karakteristik pendidikan Islam dengan pendidikan Barat. Hal ini disebabkan visi-misi maupun tujuan dari pendidikan islam terintegrasikan dalam pencapaian nilai-nilai keilahian, dimana keridhoaannya bagian dari ultimate-gool dari pendidikan islam itu sendiri. Integraslisasi dari tujuan mencakup hal-hal sebagai berikut: Pertama, dalam sistem pendidikan islam tidak ada pemisahan (dikotomi) antara nilai-nilai pendidikan moral dengan ke-Tuhanan dengan kehidupan itu sendiri; Kedua, adanya kesatuan maupun korelasi antara kehidupan di dunia dan diakherat sehingga segala bentuk perbuatan manusia di dunia dengan kehidupan setelahnya merupakan sesuatu yang tidak bisa dipisahkan. Hal ini menunjukkan bahwasannya dalam pendidikan islam perlu adanya prinsip keseimbangan (Al-Tawaazun) antara kepentingan hidup di dunia dan di akherat kelak; Ketiga, adanya keseimbangan dalam sistem pendidikan islam, dimana pendidikan akal dan pendidikan moral spiritual dimana keduanya harus menjadi kerangka bangunan yang bersifat sejajar, dimana keselarasan maupun kekuatan akal harus berbanding lurus dengan kecerdasan emosional spiritual, dimana pendidikan akal bertujuan untuk memberikan pencerahan serta mencerdaskan alam pikiran manusia, sedangkan pendidikan moralspiritual tidak lain hanya untuk membentuk kepribadian umat manusia yang memiliki dimensi akhlak, moral maupun karakter yang sejalan dengan nilai-nilai budaya dan agama; Keempat, pendidikan islam baik secara visi, misi maupun orientasinya bukan hanya menata pada wacana keindividuan semata juga prinsip kepentingan orang banyak (masyarakat). Hal ini bertujuan agar tatanan yang sudah ada dalam masyarakat dapat terbinda dan terjaga serta terawat dengan baik; Kelima, dalam system pendidikan islam paradigma hablum minallah dan hablum minannas maupun Abdullah dan khalifatullah merupakan satu kesatuan dalam satu konstruks keseimbangan antara idealitas ilahiyah dan realitas insaniyah yang mampu menciptakan tatanan perpaduan antara nilai-nilai ilahiyah, kesolehan sosial ijtimaíyah seiring dan seirama dalam mencapai sistem yang ideal; dan Keenam, konsep maupun paradigma pendidikan islam senantiasa menyeimbangkan antara pendidikan jasmani dan rohani. Kodrat kemanusiaan yang ter-

\section{REFERENCES}

al Attas, S. M. N. (1980). The Concep of Education in Islam: A Framework for an Islamic Philoshophy of Education (Kuala Lumpur: Muslim Youth Movement of diri dari unsur jasmani dan rohani harus tetap terjaga keseimbangannya dimana jasmani bukan hanya sekedar mendapatkan asupan nutrisi yang dianggap menjadi kebutuhan asasi semata melainkan masukan yang sesuai dengan nila-nilai yang sesuai dalam rambu-rambu agama harus juga jadi pertimbangan dimana bangunan jasmani yang sehat serta rohani yang kuat akan menjadi pondasi maupun tolak ukur dalam pembinaan integritas pribadi yang berkarakter. Ismalil (2003) Dengan demikian Ketuhanan Yang Maha Esa merupakan titik temu baik dalam Pancasila sebagai Dasar Negara Republik Indonesia maupun dalam tujuan pendidikan islam itu sendiri dalam membentuk kepribadian bangsa secara integral.

\section{KESIMPULAN}

Pancasila sebagai Code of Conduct dalam perjalanan sejarahnya sejak bangsa Indonesia merdeka hingga sekarang seringkali dibenturkan oleh mereka yang merasa tidak puas dan celakanya mereka mengatasnamakan agama padahal kontens maupun isi dari Pancasila sejalan dengan nilai-nilai agama. Wacana yang sering mengancam terhadap eksistensi Pancasila sebagai idiologi bagi bangsa Indonesia timbulnya fahamfaham radikal yang hanya melihat dari sisi luarnya bukan kontens maupun isi yang terkandung dalam Pancasila tersebut; sebut saja misalkan dalam Sila Pertama, Ketuhanan Yang Maha Esa merupakan salah satu bentuk intisari yang juga terdapat dalam ajaran Islam yang disebut dengan Tauhid Uluhiyah dimana keduanya dijadikan pilar utama tujuan pendidikan baik dalam tujuan pendidikan Nasional maupun dalam tujuan pendidikan Islam.

Bab II pasal 3 dalam Undang-undang SISDIKNAS Nomor 20 Tahun 2003 dikatakan bahwa tujuan pendidikan nasional adalah untuk mengembangkan potensi peserta didik agar menjadi manusia yang beriman dan bertakwa kepada Tuhan Yang Maha Esa atau dengan kata lain Sila kesatu harus dijadikan sebagai pilar bagi pola pembentukan SDM Indonesia, begitu juga dalam pendidikan islam. Konsep maupun paradigma pendidikan Islam lebih bercorak pada pembentukan nilai-nilai kesolehan, seperti nilai-nilai moral dank keTuhanan; adanya keselarasan antara tujuan hidup didunia dengan kehidupan di akherat; penyelarasan antara pendidikan akal dengan moral spiritual; kewajiban individu yang ahrus membuahkan kesolehan social (masyarakat banyak); menyatukan konsep hablum minannnas dan hamblum minallah; dan terjaganya keseimbangan antara pendidikan jasmani dan rohani. Sisi lain jika dilihat dari tugas maupun peran agama dan negara dalam wacana pendidikan mempunyai satu visi dimana pendidikan sebagai bagian dari kewajiban agama dan negara.

Malaysia (ABIM)).

Azra, A. (2012). Pendidikan Islam: Tradisi dan Modernisasi di Tengah Tantangan Millenium III (Jakarta: Kencana).

Denney, A. S. and Tewksbury, R. (????). How to write a literature review. Journal of 
criminal justice education 24, 218-234. doi: https://doi.org/10.1080/10511253. 2012.730617 .

Fuad, F. and Jurnalica (2012). Islam dan Ideologi Pancasila Sebuah Dialektika. Lex Journal 9, 164-170.

Ibrahim, A. (2010). Perspektif Futuristik Pancasila sebagai Asas/Ideologi dalam UU Keormasan. Journal Konstitusi III, 129-148.

Islam, D. J. P. A. (2011). Buku Pengayaan Guru PAI: Pendidikan Kewarganegaraan, Budaya dan Agama (Jakarta: Kementerian Agama RI).

Ismalil, F. (2003). Masa Depan Pendidikan Islam: Ditengah Kompleksitas Tantangan dan Modernitas (Jakarta: PT. Bakti Aksara Persada).

Márifah, I. (1996). Rekonstruksi Pendidikan Agama Islam: Sebuah upaya Membangun Kesadaran Multikultural untuk Mereduksi Terorisme dan Radikalisme Islam (Annual International Conference on Islamic Studies: AICIS XII).

MD, M. M. (2011). Perdebatan Hukum Tata Negara Pasca Amandemen Konstitusi (Jakarta: Rajawali Pers).

Pendidikan, N. D. (2007). Kamus Besar Bahasa Indonesia (KBBI) (Jakarta: Balai Pustaka).

PENDIS, D. J. P. I. K. R. (2011). Pendidikan Kewarganegaraan, Budaya dan Agama (Jakarta: Kementrian Agama Republik Indonesia).

Rahardjo, M. D. (2007). Intelktual Intelgensia dan Perilaku Politik Bangsa (Jakarta: Mizan).
Raho, B. (2007). Teori Sosiologi Modern (Jakarta: Prestasi Pustaka).

Wenehen, S. (2012). Pedoman Penyusunan dan Penerapan Code of Conduct untuk Sekolah: Cara Memangkas Korupsi, Kekerasan, dan Pelanggaran Etika di Lingkungan Sekolah (Jakarta: Cahaya Pineleng).

Widowati, Y. (2019). Menggali kembali Peran Pancasila sebagai Ideologi Bangsa dan Dasar Negara dalam Pembangunan HUkum Nasional di Era Globalisasi. http://repository.umy.ac.id/handle/123456789/13541.

Conflict of Interest Statement: The author declare that the research was conducted in the absence of any commercial or financial relationships that could be construed as a potential conflict of interest.

Copyright (0) 2020 Wasehudin. This is an open-access article distributed under the terms of the Creative Commons Attribution License (CC BY). The use, distribution or reproduction in other forums is permitted, provided the original author(s) and the copyright owner(s) are credited and that the original publication in this journal is cited, in accordance with accepted academic practice. No use, distribution or reproduction is permitted which does not comply with these terms. 